\title{
Risk Assessment of Water Environment Treatment PPP Projects Based on a Cloud Model
}

\author{
Yaqiong Zhang $\mathbb{D}^{1,2}$ Nan $\mathrm{He}\left(\mathbb{D},{ }^{3}\right.$ Yijing Li $\mathbb{D}^{1},{ }^{1}$ Yiyang Chen $\mathbb{D}^{4},{ }^{4}$ Lei Wang $\mathbb{D},{ }^{2}$ \\ and Yunlong Ran $\mathbb{D}^{5}$ \\ ${ }^{1}$ School of Management and Economics, North China University of Water Resources and Electric Power, \\ Zhengzhou 450045, China \\ ${ }^{2}$ Zhengzhou Railway Vocational and Technical College, Zhengzhou 451460, China \\ ${ }^{3}$ School of Public Management, North China University of Water Resources and Electric Power, Zhengzhou 450045, China \\ ${ }^{4}$ University of Chinese Academy of Sciences, Beijing 100049, China \\ ${ }^{5}$ Henan Water Valley Innovation Technology Research Institute Co., Ltd., Zhengzhou 450046, China
}

Correspondence should be addressed to Yaqiong Zhang; sharonmonster@hotmail.com and Yijing Li; 326746191@qq.com

Received 17 August 2021; Revised 17 October 2021; Accepted 26 October 2021; Published 11 November 2021

Academic Editor: Baogui Xin

Copyright $\odot 2021$ Yaqiong Zhang et al. This is an open access article distributed under the Creative Commons Attribution License, which permits unrestricted use, distribution, and reproduction in any medium, provided the original work is properly cited.

Risk assessment of public-private partnership projects has been recently acknowledged as a crucial issue in infrastructure projects. Objective assessment of risk status is conducive to the establishment of scientific and reasonable management measures. The particularity of evaluating water environment treatment PPP projects means that random errors in the evaluation index and the threshold fuzziness of evaluation degrees are issues that require attention. This paper uses the Pythagorean fuzzy cloud model to process the randomness and fuzziness of the indicators. This study assessed the risks of an iconic water environment treatment PPP project inn mid-China. The risk ranks were evaluated in terms of five dimensions: political, economic, construction completion, operational, and ecological. Moreover, the results of the evaluation were compared with results derived using a regular cloud model. It was found that the Pythagorean fuzzy cloud model produced results consistent with the regular method, while also having the advantage of reflecting the randomness and fuzziness of the evaluation indicators. According to the evaluation data in this case, the project risks were ranked as follows: political $>$ construction completion $>$ operational $>$ ecological $>$ economic. The overall project risk was medium. This study's results could provide technical support for water treatment PPP project risk assessment, indicator measurement, and statistical error control.

\section{Introduction}

Water is an indispensable resource for the development of societies, both naturally and economically [1]. The pollution of water environments and the shortage of water resources are universal problems in the world, which hinder the sustainable development of both societies and economies. Nowadays, people are paying more attention to the improvement of the natural environment rather than to economic growth; hence, the demand for water environment improvement is increasing rapidly. Such improvements require continued investment in water infrastructure projects, especially water environment treatment projects [2]. However, financial funds alone cannot meet the demands of water environment treatment projects' investment and construction [3], which has precipitated the rapid growth of PPPs (Public-Private Partnerships) in the water sector [4]. More and more countries and regions are encouraging the use of the PPP model for water environment treatment in order to attract private investors and relieve financial pressure on the government [5]. The involvement of the private sector can bring not only a large amount of capital but also advanced management expertise and innovative technologies, effectively improving the performance of water environmental treatment PPP projects [6]. As the world's largest developing country, China is also the most active PPP markets, especially in its water infrastructure. According to the China Public-Private Partnerships Center (CPPPC), 
China invested in 267 water PPP projects from 2008 to 2018, accounting for one third of the global total [7]. After 2018, there was a significant decline in the PPP market after many failed projects created a huge burden that the Chinese government had to shoulder. Many PPP projects fail when private enterprises take too many risks due to inaccurate risk assessment. To maintain sustainable development of water environmental treatment PPP projects, it is of great significance to assess the project risk scientifically and accurately [8].

Water environment treatment PPP projects are involved in ecologic, economic, and hydraulic engineering theory and knowledge. The purpose of these projects is to reduce the pollution of river basins, protect aquatic animals and plants, improve the landscape around water bodies, and create a good natural environment. These kinds of projects require significant investment and expertise as they greatly influence the surrounding environment and urban residents. Thus, as a principal investor and responsible party, the Chinese government cannot guarantee the construction and operational efficiency of the projects [9]. Moreover, water environment treatment PPP projects are very different from other infrastructure projects. First, water environment treatment PPP projects involve more stakeholders than other infrastructure projects, leading to a more complex relationship system. For example, if residents' dump sewage into the watershed and obstruct water treatment, the progress of a project will be greatly affected. Second, the performance evaluation of water environment treatment PPP projects is usually based more on qualitative than on quantitative indicators. The scoring standards and language expressions of experts have more influence on project risk assessment than quantitative indicators do. Finally, the current method of risk assessment is mainly used in projects with clear outputs, such as highway projects and sewage treatment projects. However, water environment treatment PPP projects with no clear outputs rely on government fees or package peripheral fees rather than user fees, which randomly generate more risks and require more suitable risk assessment methods. Therefore, it is necessary to comprehensively consider the relationship between stakeholders and the risks generated from these relationships while also considering the fuzziness and randomness of risk indicators at the same time.

Most researchers focus on the identification of risk factors, risk distribution, and the impact of risk on project performance of water environment treatment PPP projects. $\mathrm{Xu}$ and Yang [10] identified 11 key risk factors in China's water environment treatment PPP projects using a case study and developed a risk distribution mechanism. Nguyen et al. [11] identified 22 key risk factors affecting the sustainability of highway PPP projects from the perspective of stakeholders and evaluated project risks. Shrestha et al. [5] introduced a general risk distribution method based on the literature on 25 kinds of risk factors and the comments of 32 experts in China's water infrastructure industry. Sobiei [12] adopted the neural network and a framework for quantitatively identifying, evaluating, and responding to risk in construction. Ameyaw [13-15] used fuzzy set approach in the Delphi method to deal with the ambiguity of linguistic terms to minimize the fuzziness of qualitative expert examination in water infrastructure PPP projects. Above all, the methods used in these studies are usually the analytic hierarchy process (AHP) [16], fuzzy comprehensive evaluation [17], and Monte Carlo simulation [18]. The results of different methods vary greatly mainly due to the large proportion of qualitative evaluation indicators in the evaluation index system [19]. Both the fuzziness and randomness of risk indicators have an impact on the evaluation results, but the existing studies usually consider only fuzziness [13-17] or randomness [18], rather than both aspects at the same time. Moreover, few scholars have paid attention to the impact of inaccurate qualitative indicators of risk assessment for water environment treatment PPP projects. All these issues provide research space for this study.

To bridge the research gap, this paper adopts the cloud model to simultaneously consider the fuzziness and randomness of the risk indicators by its eigenvalues of expectation $\left(E_{x}\right)$, entropy $\left(E_{n}\right)$, and hyperentropy $\left(H_{e}\right)$. When determining indicator's weight, the Pythagorean fuzzy set was used to process the fuzziness of expert ratings in the cloud model. So, the cloud model with the Pythagorean fuzzy set is the right choice for studying two kinds of uncertainty. The rest of this paper is organized as follows. In Section 2, a literature review is conducted. Section 3 explains the cloud model and the Pythagorean fuzzy AHP method. In Section 4, a case study of water environment treatment PPP project is analyzed to demonstrate the application of the proposed method and validate it. Section 5 discusses the risk factors influencing water environment treatment PPP projects and compares the results with those of a regular cloud model. Finally, conclusions are drawn and limitations are discussed in Section 6.

\section{Literature Review}

2.1. Risk Evaluation Methods for PPP Projects. PPP projects are more complex than any other infrastructure PPP projects due to their massive investment scale and the multiple stakeholders that are involved in their extremely long life cycle. Therefore, insufficient or improper risk management measures may cause severe problems during the long project lifecycle, which could lead the failure to the project. [13]. Thus, PPP risk management is still one of the most common topics in PPP academic research in China and the worldwide [20].

Previous studies on PPP project risk mainly focused on risk identification, risk assessment, and risk allocation [21]. (i) Risk identification: $\mathrm{Xu}$ et al. [22] identified 17 key risk factors in PPP projects, among which government intervention seemed to be the most critical. Chan et al. [23] found 34 major risks affecting PPP projects in China. (ii) Risk assessment: Thomas et al. [24] evaluated risk probability and its impact based on fuzzy fault tree analysis and the Delphi method and applied it to PPP projects. Wu et al. [25] combined 2-dimensional language information with a cloud model to evaluate risk in a waste incineration power generation project. (iii) Risk allocation: Ameyaw and Chan 
[13] adopted a fuzzy method and found 13 modes of risk allocation in water PPP projects. In the context of the increasingly complex structure of PPP projects, scholars are constantly developing new risk assessment methods to ensure the smooth operation of the projects. For example, Valipour et al. [26] introduced new risk assessment criteria by using stepwise weighting assessment ratio analysis and complex ratio. Wu et al. [27] adopted a 3-dimensional model, including probability, loss, and uncontrollability, to conduct risk assessment and then used AHP and the gray fuzzy method to evaluate project risks. Li and Wang [28] proposed a systematic and practical risk assessment method by combining the ISM method and network process. Although these studies provide insight into PPP project risk, additional attention should be given to risk assessment because it is to the success of the PPP projects [5].

The above scholars adopted the analytic hierarchy process (AHP) [16], the fuzzy comprehensive evaluation method [17], or Monte Carlo simulation [18] when assessing project risk, but some obvious disadvantages exist for each of these methods. First, AHP is too general and subjective. Second, in the fuzzy comprehensive evaluation method, the value of the membership function is used to replace the fuzzy number, so the uncertainty of the evaluation cannot be well reflected [29]. Finally, Monte Carlo simulation cannot determine the probability distribution of each risk variable. Filling all these research gaps, the cloud model uses three eigenvalues to realize the transformation from qualitative indicators to quantitative data; it can not only reflect fuzziness in the evaluation results but also account for randomness and fuzziness while the model is being built.

2.2. Risk Factors of Water Environment Treatment PPP Projects. The first step of risk assessment is risk identification, which is an elementary and important step for risk management [30]. Most risk factors and their evaluations are influenced by the characteristics of the target industry [13]. Compared with other types of infrastructure PPP projects, water environment treatment PPP projects have more stakeholders, which form a more complex relationship structure [5] and bring more conflict. First of all, different interest demands will affect the behavior of stakeholders, which in turn will affect project performance. Whereas the government pursues the maximization of public interests and the private sector pursues the maximization of investment returns. Second, water environment treatment PPP projects have more significant social and economic impacts than other types of infrastructure PPP projects. Water security is a fundamental condition for socio-economic development and urbanization, and it has a strong causal relationship with economic growth and social progress [31]. However, in the process of project risk evaluation, many indicators are difficult to quantitatively evaluate, and scientific methods are needed to transform qualitative data into quantitative data. Finally, water environment treatment PPP projects usually have a strong external effect. The composition of PPP projects' profit is a simplex of social and external benefits, which greatly changes the proportion of risk allocation in PPP projects. Thus, more refined risk identification and evaluation methods are needed to make the whole process more scientific and effective in water environment treatment PPP projects.

There are a few studies on risk identification in water environment treatment PPP projects. Choi et al. [4] analyzed a PPP project in China's water utilities' market and determined the risk factors faced by foreign companies entering the Chinese market. Ameyaw and Chan [13] used the fuzzy comprehensive evaluation method to assess and rank risk factors in a water supply PPP project in a developing country. However, many risk identification methods are not effective when applied to water environment treatment PPP projects because of their unique industrial background. Therefore, this paper mainly focuses on developing an indicator system and assessing the fuzziness, randomness, and uncertainty of indicators in project risk identification and evaluation to make the risk evaluation of water environment treatment PPP projects more scientific and reasonable.

It is generally accepted that the key risk categories of PPP projects include political risk [13], economic risk [32], operational risk [5], environment risk [33], and construction risk [2]. Based on research on these risk categories, this paper adopted the method of literature reviews and a questionnaire survey to construct a risk evaluation index system for water environment treatment PPP projects. Accordingly, 35 critical factors are identified, as shown in Table 1.

To build a 2-level indicator system from previous list, questionnaires (shown in Supplementary material (available here)) were distributed to 150 recipients between September 2018 to June 2019, which was in the first year after this project was built, and 122 were returned. For previous research studies of infrastructure projects $[57,58]$, this sample size was enough for this research. The recipients were selected from six departments of the water environment treatment PPP project team and three research institutes. In order to fully consider stakeholders on all sides, we selected sample groups from the local government, the private sector, the contracting industry, a research institution, the water resource department, and a pool of experienced PPP experts from various institutions.

Using a combination of the literature review and the questionnaire responses, five first-level indicators were screened: political risk, economic risk, construction completion risk, operational risk, and ecological risk; 25 secondlevel indicators were also evaluated. Based on the data from the questionnaires and the accumulated risk factors, this research identified a risk assessment indicator system, as shown in Table 2.

\section{Methodology}

3.1. Understanding the Cloud Model. The cloud model can transform an evaluation indicator from a qualitative concept into a quantitative description [59]. On the 
TABLE 1: Risk identification.

\begin{tabular}{|c|c|c|}
\hline Risk factor & Risk category & Source \\
\hline Corruption & Political & {$[34,35]$} \\
\hline Government's intervention & Political & [34-38] \\
\hline Expropriation by government & Political & {$[36-39]$} \\
\hline Government's reliability & Political & {$[35,38,40-42]$} \\
\hline Political/public's conflict & Political & {$[34,38,40]$} \\
\hline Legislative changes & Political & {$[36,38,43]$} \\
\hline Change in interest rate & Economic & {$[34-36,38,40,42]$} \\
\hline Foreign exchange and convertibility & Economic & {$[34,36,38]$} \\
\hline Inflation & Economic & {$[34,35,38,40]$} \\
\hline Delay by government's decision-making & Political & {$[34,40,44,45]$} \\
\hline Delay by complex approval process & Political & {$[36,38,40]$} \\
\hline Conflict or uncomplete contract & Operation & {$[34,35,38,40]$} \\
\hline Financial crises & Financial & {$[34,38,40]$} \\
\hline Project completion risk & Construction & {$[35,36,38]$} \\
\hline Technology risk & Construction & {$[36,38]$} \\
\hline Change in market demand & Economic & {$[34,38,40,43]$} \\
\hline Change in market price & Economic & {$[35,36]$} \\
\hline Force majeure & Political & {$[34,36,40,46]$} \\
\hline Coordination and management risk & Operation & {$[36,40,43]$} \\
\hline Environmental protection & Construction & {$[40,47]$} \\
\hline Regime stability & Political & {$[43]$} \\
\hline Flawed legal system & Political & {$[43]$} \\
\hline Delay in construction & Construction & {$[34,38,43]$} \\
\hline Credit risk & Construction & {$[38,48]$} \\
\hline Profit share risk & Operation & {$[49-51]$} \\
\hline Cost over run & Operation/construction & {$[43,50,52,53]$} \\
\hline Project quality risk & Construction & {$[34,43,50,52]$} \\
\hline Project design risk & Economic & {$[34,49,50]$} \\
\hline Landscaping risk & Ecological & {$[39,48,54]$} \\
\hline Soil erosion & Ecological & [55] \\
\hline Biological chain destruction & Ecological & {$[48,49,54]$} \\
\hline Solid waste pollution & Ecological & {$[43,48,49,52,53,56]$} \\
\hline Public perception and satisfaction & Ecological & {$[43,49-51,53]$} \\
\hline Water resource utilization & Ecological & {$[48,49,54]$} \\
\hline Land acquisition & Political & Interview \\
\hline
\end{tabular}

contrary, the comprehensive index assessment method does not consider the uncertainty of the index, and the fuzzy assessment method only considers the fuzziness of the index but neglects the randomness. At present, the cloud model has been widely applied in data mining [60], evaluating air/water quality [61], evaluating the capacity of water environments [62], etc. In this paper, the cloud model approach is adopted to deal with the fuzziness and randomness of indicators in project risk evaluation. Moreover, the cloud model also considers the cognitive aspect of experts' rating of weight determinations using Pythagorean fuzzy numbers (PFNs), to reduce their randomness and fuzziness.

In a cloud model, a set of precise numbers of the values of $U$ represents the quantitative domain. $C$ is the set of qualitative concepts in set $U$. Let $\forall x \in U$, where $x$ is a random implementation of the qualitative concept $C$. The degree of certainty of $x$ for concept $C_{\mu}(x) \in[0,1]$, which is noted as "membership," is a set of random numbers that tend to be stable [40], where $\mu: U \longrightarrow[0,1], \forall x \in U$, $x \longrightarrow \mu(x)$; the final form composed by all $x \mathrm{~s}$ in domain $U$ is called a cloud, in which each $x$ is a cloud drop of the cloud
[63]. A cloud model can transform the qualitative concepts of an index system into quantitative representations. One cloud drop represents a random event, which can be understood as a probability distribution function that represents the randomness of a qualitative concept. The certainty of a cloud drop represents the fuzziness of a qualitative concept, which can be understood as membership based on the fuzzy set theory.

The eigenvalues of the cloud model are usually composed of 3 digits $\left(E_{x}, E_{n}, H_{e}\right)$ : expectation $\left(E_{x}\right)$, entropy $\left(E_{n}\right)$, and hyperentropy $\left(H_{e}\right)$. Expectation measures the certainty of the qualitative concept; entropy measures the scope of uncertainty by its fuzziness and randomness; hyperentropy measures the uncertainty of entropy. An illustration of a standard cloud is shown in Figure 1 . The larger $\left(E_{n}\right)$ is, the larger the acceptance range of the qualitative description will be. The larger $\left(H_{e}\right)$ is, the more dispersed the cloud will be; the greater the number of the clouds, the clearer the shape of the cloud.

The forward cloud generator obtains a series of cloud drops by inputting three digits eigenvalues, and the specific steps for calculating the three digits as follows: 
TABLE 2: Evaluation indicators in water environment treatment PPP project risks.

\begin{tabular}{lc}
\hline $1^{\text {st }}$-level indicator of risk & $2^{\text {nd }}$-level risk indicator of risk \\
\hline$U_{1}$ Political & $U_{11}$ Legislative changes \\
& $U_{12}$ Government intervention \\
$U_{13}$ Land acquisition & $U_{14}$ Unstable law or rules \\
\hline & $U_{21}$ Interest rate \\
$U_{2}$ Economic & $U_{22}$ Financial/exchange rate risk \\
& $U_{23}$ Inflation risk \\
& $U_{24}$ Land compensation standard \\
\hline & $U_{31}$ Technology risk \\
$U_{3}$ Construction & $U_{32}$ Construction cost overrun \\
completion & $U_{33}$ Delay in supply \\
& $U_{34}$ Project quality risk \\
\hline & $U_{41}$ Profit risk \\
& $U_{42}$ Operation management risk \\
$U_{4}$ Operational & $U_{43}$ Default risk \\
& $U_{44}$ Supporting facilities \\
& $U_{45}$ Operator change \\
& $U_{46}$ Operation cost overrun \\
\hline & $U_{51}$ Landscaping risk \\
& $U_{52}$ Soil erosion \\
$U_{5}$ Ecological & $U_{53}$ Biological chain destruction \\
& $U_{54}$ Water pollution \\
$U_{55}$ Solid waste pollution \\
$U_{56}$ Public perception and \\
involvement
\end{tabular}

(1) Generate standard random numbers $E_{n_{i}}=\operatorname{NORM}\left(E_{n}, H_{e}^{2}\right)$ by using Python, where $E_{n}$ is the expectation and $H_{e}$ is the standard deviation

(2) Generate standard random numbers $x_{i}$, where $H_{e}$ is the expectation and $E_{n_{i}}$ is the standard deviation, here $x_{i}$ is the cloud drops

(3) Calculate $\mu_{i}$, the membership of $x_{i}$, to obtain the coordinator of the cloud drop $\left(x_{i}, \mu_{i}\right)$ by using $\mu_{i}=\exp \left[-\left(x_{i}-E_{x}\right)^{2} / 2 E_{n i}^{2}\right]$
(4) Repeat Steps 1-3 until there are $n$ drops in the cloud model

Unlike the forward cloud generator, the backward cloud generator transmits the qualitative data into quantitative data noted by $\left(E_{x}, E_{n}, H_{e}\right)$. To calculate $N$ given numbers of cloud drops $x_{j}$, the steps are as follows:

(1) Calculate the mean $\bar{X}$ (or $E_{x}$ ) by cloud drops $x_{j}$ :

$$
\begin{aligned}
\bar{X} & =\frac{1}{N} \sum_{j=1}^{N} x_{j}, \\
E_{x} & =\bar{X} .
\end{aligned}
$$

(2) Calculate $E_{n}$ through $x_{j}$ and $E_{x}$ :

$$
E_{n}=\sqrt{\frac{\pi}{2}} \frac{1}{N} \sum_{j=1}^{N}\left|x_{j}-\bar{X}\right| .
$$

(3) Let $H=k$ (where $k$ is a norm, which can be adjusted as needed).

3.2. The Process of Pythagorean Cloud Model. In a cloud model, a standard cloud graph represents the risk ranks of five risk levels, from the lowest to the highest, as a reference object. After determining an indicator's weight, the eigenvalues of the cloud model can be calculated to draw an indicator specific cloud. This specific cloud represents the eigenvalues of one first-level indicator rank. Ultimately, locating each of the indicator specific clouds in the standard cloud shows the risk level assessment of the five first-level indicators. Here, Python was chosen to achieve such an evaluation based on the cloud model, see steps in Figure 2.

3.2.1. Ensure Indicator Grade Threshold. According to the overview of water environment treatment PPP projects in China, the evaluation grade threshold can be divided into five categories:

$$
\begin{aligned}
L=\left\{L_{1}, L_{2}, L_{3}, L_{4}, L_{5}\right\} & =\{\text { really low risk, low risk, medium risk, medium high risk, high risk }\} \\
& =\{(0,30) ;[30,50) ;[50,70) ;[70,90) ;[90,100)\} .
\end{aligned}
$$

To value a unilateral boundary value of $\left[C_{\min },+\infty\right)$ or $\left(-\infty, C_{\max }\right]$, it is necessary to verify the parameters or expectations of the default boundary before transforming the data into cloud eigenvalues. A cloud model can then be built to describe the risks of the project based on this grade threshold. Function (4) is used to transform the qualitative data into the 3-digit qualitative eigenvalues of the cloud model. $k$ is constant.

$$
\left\{\begin{array}{l}
E_{x}=\frac{C_{\max }+C_{\min }}{2}, \\
E_{n}=\frac{C_{\max }-C_{\min }}{6}, \\
H_{e}=k .
\end{array}\right.
$$




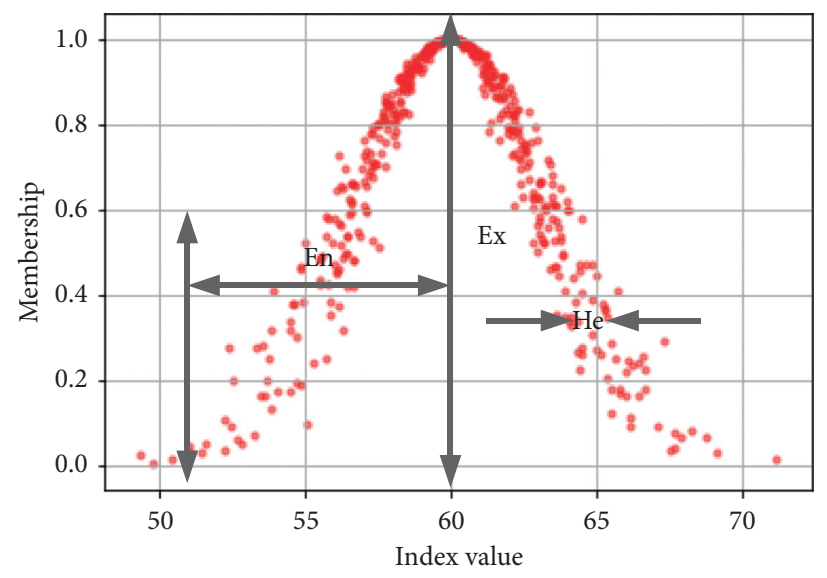

FIGURE 1: Illustration of a standard cloud model by its eigenvalues $\left(E_{x}, E_{n}, H_{e}\right)$.

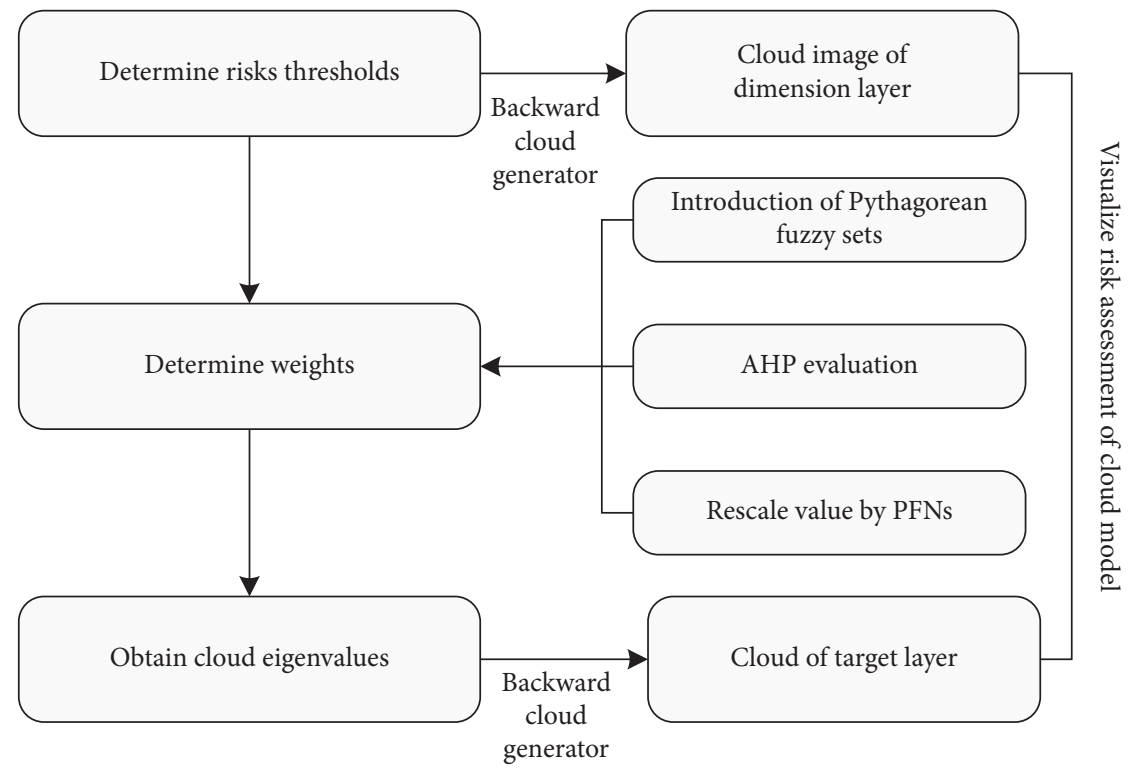

Figure 2: Flowchart of project risk assessment using a cloud model.

Based on previous research, let $k=0.5$, so the thresholds for the indicator standard cloud would be as follows: really low risk, indicated in the color of dark blue $(0,10,0.5)$, low risk, indicated in green $(40,10 / 3,0.5)$, medium risk, indicated in light blue $(60,10 / 3,0.5)$, medium-high risk, indicated in black $(80,10 / 3,0.5)$, and high risk, indicated in purple $(100,10 / 3,0.5)$. Figure 3 graphically shows these thresholds.

3.2.2. Determination of Indicator Weight. The analytic hierarchy process (AHP) method was widely used in determining indicator's weight [64]. However, the component of project stakeholders is so complicated that their activities are unpredictable. Additionally, the linguistic comment set for risk evaluation contains fuzziness and randomness. Thus, the Pythagorean fuzzy set (PFS) is used to determine the weight of indicators and extend the AHP method. As the information solicited requires the participants to have indepth knowledge and empirical experience about risks, the participants needed to meet at least one of the following criteria [42, 57]: (i) extensive working experience in water PPP projects in China; (ii) current/recent working experience on infrastructure risk management; (iii) in-depth understanding of the concept of PPP risks.

(1) Understanding the Pythagorean fuzzy AHP: AHP, which was first proposed by Saaty, is one of the most popular multicriteria decision-making methods. The classical AHP method takes decision makers and their opinions into consideration in order to make a multiple criteria evaluation. To deal with the fuzziness and randomness of indicators, the classic fuzzy set and the intuitionistic fuzzy set have been widely used. However, intuitionistic fuzzy sets have certain limitations. The sum of membership and nonmembership of the scheme satisfying the attributes cannot be greater than 1 . In the case of such a limitation, Pythagorean fuzzy numbers (PFNs) can rectify the problems [65-67]. PFNs can reallocate the 


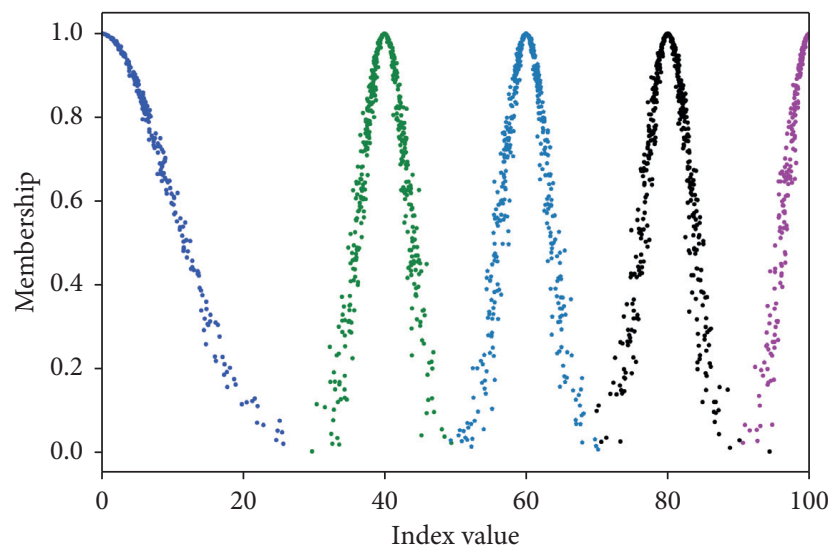

FIGURE 3: Standard cloud map of risks evaluation grade thresholds.

scale set of the judgement matrix in the AHP. The new matrix with PFNs is obtained to finish the process of determining the weights. Thus, Pythagorean fuzzy AHP can be an appropriate method for building a cloud model because of its weight determination step.

(2) Rescaling the judgement matrix using Pythagorean fuzzy AHP: let $X$ be the domain so that $A=\left\{x, \mu_{A}(x), v_{A}(x) x \in X\right\}$ is the PFS, with $\mu_{A}: X \longrightarrow[0,1]$ and $v_{A}: X \longrightarrow[0,1]$ being the membership and nonmembership of $A$ in domain $X$. For every $x \in X$ satisfying $\mu_{A}^{2}(x)+v_{A}^{2}(x) \leq 1$, $\pi_{A}(x)=\sqrt{1-\mu_{A}^{2}-v_{A}^{2}(x)}$ represents the hesitation or uncertainty of $X$ on $A$. $\beta=\mu_{\beta}, v_{\beta}$ is called the set of Pythagorean fuzzy numbers, or the PFNs [68]. Use $i$ and $j$ to define the risk indicators.

By rescaling the AHP judgement matrix with PFNs, a new matrix scale is obtained. A comparison of the newly obtained scores to the regular AHP scores is clearly shown in Table 3 [69].

Step 1: create a pairwise comparison matrix $\bar{A}$ as given in Table 2:

$$
\bar{A}=\left(\left[\begin{array}{ccc}
A & \cdots & a_{1 n} \\
\vdots & \ddots & \vdots \\
a_{n 1} & \cdots & A
\end{array}\right]\right) .
$$

where $A$ is $([0.4,0.55),[0.4,0.55])$, while $a$ is $\left(\left[\mu_{L}, \mu_{U}\right],\left[v_{L}, v_{U}\right]\right)$.

Step 2: obtain differences of the matrix between risk indicator $i$ and $j$ by using (6) and (7):

$$
\begin{gathered}
d_{i K L}=\mu_{i K L}^{2}-v_{i K L}^{2}, \\
d_{i K U}=\mu_{i K U}^{2}-v_{i K U}^{2} .
\end{gathered}
$$

Step 3: obtain the interval multiplicative matrix using equations (8) and (9):
TABLE 3: Evaluation scores for weight vectors in AHP and PFNs.

\begin{tabular}{lccc}
\hline \multirow{2}{*}{ Linguistic terms (from $i$ to $j$ ) } & AHP score & \multicolumn{2}{c}{ PFNs } \\
& & $\mu_{L} \mu_{U}$ & $v_{L} v_{U}$ \\
\hline Equally important & 1 & {$[0.4,0.55]$} & {$[0.4,0.55]$} \\
Slightly important & 3 & {$[0.5,0.65]$} & {$[0.3,0.45]$} \\
Obviously important & 5 & {$[0.6,0.75]$} & {$[0.2,0.35]$} \\
Very important & 7 & {$[0.7,0.85]$} & {$[0.1,0.25]$} \\
Extremely important & 9 & {$[0.8,0.95]$} & {$[0.0,0.15]$} \\
Slightly unimportant & $1 / 3$ & {$[0.3,0.45]$} & {$[0.5,0.65]$} \\
Obviously unimportant & $1 / 5$ & {$[0.2,0.35]$} & {$[0.6,0.75]$} \\
Very unimportant & $1 / 7$ & {$[0.1,0.25]$} & {$[0.7,0.85]$} \\
Extremely unimportant & $1 / 9$ & {$[0.0,0.15]$} & {$[0.8,0.95]$} \\
\hline
\end{tabular}

$$
\begin{gathered}
S_{i K L}=\sqrt{1000^{d_{i K L}}}, \\
S_{i K U}=\sqrt{1000^{d_{i K U}}} .
\end{gathered}
$$

Step 4: calculate the determinacy value of matrix $\bar{A}$ :

$$
\tau_{i K}=1-\left(\mu_{i K U}^{2}-\mu_{i K L}^{2}\right)-\left(v_{i K U}^{2}-v_{i K L}^{2}\right) .
$$

Step 5: multiply the determinacy value of matrix $\bar{A}$ to obtain the weights' matrix $t_{i K}$ :

$$
t_{i K}=\left(\frac{S_{i K L}+S_{i K U}}{2}\right) * \tau_{i K} .
$$

Step 6: compute the normalized priority weights:

$$
\omega_{i}=\frac{\sum_{k=1}^{m} t_{i K}}{\sum_{i=1}^{m} \sum_{k=1}^{m} t_{i K}} .
$$

Step 7: perform a consistency test of the judgement matrix:

$$
\begin{aligned}
\lambda_{\max }(\bar{A}) & =\sum_{i=1}^{n} \frac{(\bar{A} \omega)_{i}}{n \omega_{i}}, \\
\mathrm{CI} & =\frac{\lambda_{\max }-n}{n-1}, \\
\mathrm{CR} & =\frac{\mathrm{CI}}{\mathrm{RI}},
\end{aligned}
$$

where $\bar{A}$ is the judgement matrix, $(\bar{A} \omega)_{i}$ is the $i^{\text {th }}$ element in the matrix, $\lambda_{\max }(\bar{A})$ is the maximum eigenvalue of the judgement matrix $(\bar{A})$, and $\mathrm{CI}$ is the consistency test index. If $\mathrm{CI}=0,(\bar{A})$ is absolutely consistent, and RI is the average random consistency index of $(\bar{A})$. When $\mathrm{CR} \leq 0.1$, the judgement matrix passes the consistency test. As per common knowledge, if $\mathrm{CR}>0.1$, then $(\bar{A})$ has failed the consistency test. In that case, the matrix needs to be reconstructed; steps are as shown in Figure 4.

The Pythagorean fuzzy AHP interval matrix scalar is built up in Table 4. 


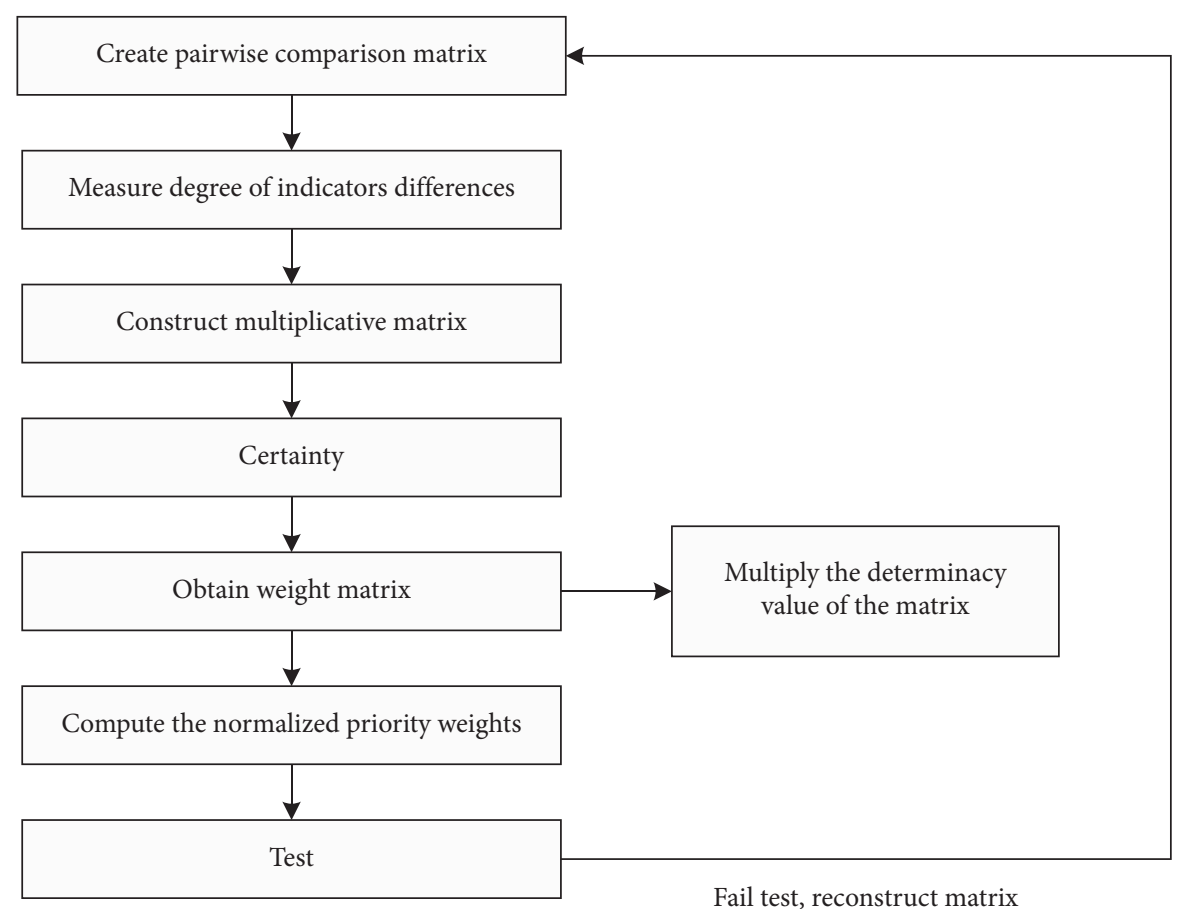

Figure 4: Steps to obtain weight by using Pythagorean fuzzy AHP.

TABle 4: Pythagorean fuzzy scale set interval weight matrix.

\begin{tabular}{lcccc}
\hline \multirow{2}{*}{ No. } & \multicolumn{2}{c}{ PFNs } & $\tau_{i K}$ & $t_{i K}$ \\
& $\mu_{L} \mu_{U}$ & $v_{L} v_{U}$ & & \\
\hline$A$ & {$[0.4,0.55]$} & {$[0.4,0.55]$} & 0.715 & 0.7150 \\
$B$ & {$[0.5,0.65]$} & {$[0.3,0.45]$} & 0.715 & 1.3856 \\
$C$ & {$[0.6,0.75]$} & {$[0.2,0.35]$} & 0.715 & 2.7137 \\
$D$ & {$[0.7,0.85]$} & {$[0.1,0.25]$} & 0.715 & 5.3698 \\
$E$ & {$[0.8,0.95]$} & {$[0,0.15]$} & 0.715 & 10.7297 \\
$F$ & {$[0.3,0.45]$} & {$[0.5,0.65]$} & 0.715 & 0.3729 \\
$G$ & {$[0.2,0.35]$} & {$[0.6,0.75]$} & 0.715 & 0.1966 \\
$H$ & {$[0.1,0.25]$} & {$[0.7,0.85]$} & 0.715 & 0.1047 \\
$I$ & {$[0.0,0.15]$} & {$[0.8,0.95]$} & 0.715 & 0.0563 \\
\hline
\end{tabular}

3.2.3. Calculation of the Eigenvalues of the Cloud Model. Ratings from experts, $E_{x 1} \cdots E_{x n}$, and their weights, $\omega_{1} \cdots \omega_{n}$, are obtained in the first two steps using equations (1) and (2). Then, the floating cloud algorithm [70] is used to calculate the eigenvalues $\left(E_{x}, E_{n}, H_{e}\right)$ of the second-level indicators of the cloud model, for there is a small correlation and each element is basically independent:

$$
\left\{\begin{array}{l}
E_{x}=\frac{E_{x 1} \omega_{1}+E_{x 2} \omega_{2}+\cdots+E_{x n} \omega_{n}}{\omega_{1}+\omega_{2}+\cdots+\omega_{n}}, \\
E_{n}=\frac{E_{n 1} \omega_{1}^{2}+E_{n 2} \omega_{2}^{2}+\cdots+E_{n n} \omega_{n}^{2}}{\omega_{1}^{2}+\omega_{2}^{2}+\cdots+\omega_{n}^{2}}, \\
H_{e}=\frac{H_{e 1} \omega_{1}^{2}+H_{e 2} \omega_{2}^{2}+\cdots+H_{e n} \omega_{n}^{2}}{\omega_{1}^{2}+\omega_{2}^{2}+\cdots+\omega_{n}^{2}},
\end{array}\right.
$$

where $E_{x \eta}$ is expectation/mean of the experts' ratings, $E_{n 1}$ is the entropy, $H_{\mathrm{en}}$ is the hyperentropy, $\omega$ is the weights of the ratings, and $n$ is the number of second-level elements.

To compute the eigenvalues of the first-level indicators, it is necessary to integrate the second-level indicators. This is a conceptual upgrade that combines two or more clouds into a generalized one. Here, we adopted the virtual cloud comprehensive algorithm [70] to figure out cloud eigenvalues for the whole project risk evaluation:

$$
\left\{\begin{array}{l}
E_{x}=\frac{E_{x 1} E_{n 1} \omega_{1}+E_{x 2} E_{n 2} \omega_{2}+\cdots+E_{x n} E_{n n} \omega_{n}}{E_{n 1} \omega_{1}+E_{n 2} \omega_{2}+\cdots+E_{n n} \omega_{n}}, \\
E_{n}=E_{n 1} \omega_{1}+E_{n 2} \omega_{2}+\cdots+E_{n n} \omega_{n}, \\
H_{e}=\frac{H_{e 1} E_{n 1} \omega_{1}+H_{e 2} E_{n 2} \omega_{2}+\cdots+H_{e n} E_{n n} \omega_{n}}{E_{n 1} \omega_{1}^{2}+E_{n 2} \omega_{2}^{2}+\cdots+E_{n n} \omega_{n}^{2}},
\end{array}\right.
$$

where $E_{x n}$ is the eigenvalues of the second-level indicators, which are from equation (16). Similarly, $E_{n 1}$ is the entropy. $H_{\text {en }}$ is the hyperentropy. $\omega$ is the weight calculated by the Pythagorean fuzzy AHP method. $n$ is the number of secondlevel elements.

\section{Case Study}

Case study analysis is used to consider "how" and "why" problems in a real-life context [71]. In this case, an actual ecological water PPP project called the Yinma River project in Xuchang, China, was adopted. This case addresses a "how" question in order to understand how a cloud model can be used scientifically in a water environment treatment PPP project. This project was not randomly selected, but was 
chosen because it is a typical case. As one of the first PPP projects for water environment treatment, the Yinma River project is located in a disadvantaged city in central China with a scarcity of water. This project was built to maintain the surface soil, underground water, and fish habitat, as well as the area's biodiversity. Therefore, it has been highly supported by the local government using the PPP model for financing and managing. The investment in the project has been massive for the city, costing about $82,816,420 \mathrm{RMB}$, and it has been financially supported by China Development Bank. Because the cooperation procedure between the public and private sectors is immature, the risk assessment of water environment treatment PPP projects is even more meaningful.

Working with the government, the private sector participant in the project is the Xuchang Water Ecology Investment Development Co., Ltd., which was jointly established by the Henan Water Resources Investment Group Co., Ltd. and the Xuchang City Investment Corporation. The private sector is responsible for the project construction, financial management, project quality control, and safety supervision. The project's construction period was two years; thereafter, its operational period is up to 30 years. According to the contract, this is a quasi-profit project whose purpose is to implement the overall plan of Xuchang City. The content of the project includes the construction of riverside landscaping and the protection and restoration of water ecosystems in order to improve citizens' happiness index. Moreover, the project stimulates the tourism industry and economy due to its unique urban river landscape.

According to the Pythagorean fuzzy AHP process, as shown in Figure 4, and the principles of interviewing experts, the index weight is evaluated. Then, equations (5)-(12) are used to determine the weights, and equations (13)-(15) are used to do the consistency test. Results are displayed in Tables 5-9.

Furthermore, a backward cloud generator is used to get the eigenvalues of the first-level index using equation (16). Finally, equation (17) is used to obtain the total project risk. Eigenvalues of indicators represent the significance of the risks, as shown in Table 10. The more significant the indicator, the more critical the risk. As mentioned before, $H_{e}=0.5$.

The first-level index in Table 10 are defined as a red cloud, in which every eigenvalue is visualized by Python through the backward cloud generator. Then, the indicator specific cloud is located in the standard cloud, as mentioned in 3.2.1. The risk assessment results of each level and of the whole project are clearly shown in Figures 5-10.

\section{Discussion}

The results show that the total risk of the Yinma River project is rated as medium, see Figure 10. With regard to the efficiency of the method to measure the water environment treatment PPP project risk, the results obtained by both the Pythagorean fuzzy cloud model and the traditional cloud model yielded similar conclusions, as shown in Table 11.
TABLE 5: Indicator judgement matrix and the weights of the political risk.

\begin{tabular}{lccccc}
\hline$U_{1}$ & $U_{11}$ & $U_{12}$ & $U_{13}$ & $U_{14}$ & $\omega$ \\
\hline$U_{11}$ & 0.715 & 1.3856 & 2.7137 & 5.3698 & 0.5210 \\
$U_{12}$ & 0.3729 & 0.715 & 1.3856 & 2.7137 & 0.2675 \\
$U_{13}$ & 0.1966 & 0.3729 & 0.715 & 1.3856 & 0.1388 \\
$U_{14}$ & 0.1047 & 0.1966 & 0.3729 & 0.715 & 0.0728 \\
$\lambda$ & 4.05402 & CI & 0.018007 & $\mathrm{CR}$ & 0.020007 \\
\hline
\end{tabular}

TABLE 6: Indicator judgement matrix and the weights of the economic risk.

\begin{tabular}{lccccc}
\hline$U_{2}$ & $U_{21}$ & $U_{22}$ & $U_{23}$ & $U_{24}$ & $\omega$ \\
\hline$U_{21}$ & 0.715 & 1.3856 & 5.3698 & 0.3729 & 0.3228 \\
$U_{22}$ & 0.3729 & 0.715 & 1.3856 & 0.3729 & 0.1657 \\
$U_{23}$ & 0.1047 & 0.3729 & 0.715 & 0.1047 & 0.0632 \\
$U_{24}$ & 1.3856 & 1.3856 & 5.3698 & 0.715 & 0.4482 \\
$\lambda$ & 4.17004 & CI & 0.05681 & CR & 0.062979 \\
\hline
\end{tabular}

TABLE 7: Indicator judgement matrix and the weights of the construction completion risk.

\begin{tabular}{lccccc}
\hline$U_{3}$ & $U_{31}$ & $U_{32}$ & $U_{33}$ & $U_{34}$ & $\omega$ \\
\hline$U_{31}$ & 0.715 & 1.3856 & 2.7137 & 0.3729 & 0.2835 \\
$U_{32}$ & 0.3729 & 0.715 & 1.3856 & 0.3729 & 0.1726 \\
$U_{33}$ & 0.1966 & 0.3729 & 0.715 & 0.1047 & 0.0771 \\
$U_{34}$ & 1.3856 & 1.3856 & 5.398 & 0.715 & 0.4668 \\
$\lambda$ & 4.10067 & CI & 0.033557 & CR & 0.037285 \\
\hline
\end{tabular}

TABLE 8: Indicator judgement matrix and the weights of the operational risk.

\begin{tabular}{lccccccc}
\hline$U_{4}$ & $U_{41}$ & $U_{42}$ & $U_{43}$ & $U_{44}$ & $U_{45}$ & $U_{46}$ & $\omega$ \\
\hline$U_{41}$ & 0.715 & 1.3856 & 2.7137 & 5.3698 & 1.3856 & 2.7137 & 0.3559 \\
$U_{42}$ & 0.3729 & 0.715 & 1.3856 & 1.3856 & 0.3729 & 2.7137 & 0.1639 \\
$U_{43}$ & 0.1966 & 0.3729 & 0.715 & 1.3856 & 0.3729 & 1.3856 & 0.1059 \\
$U_{44}$ & 0.1047 & 0.3729 & 0.3729 & 0.715 & 0.1966 & 1.3856 & 0.0688 \\
$U_{45}$ & 0.3729 & 1.3856 & 1.3856 & 2.7137 & 0.715 & 5.3698 & 0.2558 \\
$U_{46}$ & 0.1966 & 0.1966 & 0.3729 & 0.3729 & 0.1047 & 0.715 & 0.0497 \\
$\lambda$ & 6.27597 & $\mathrm{CI}$ & 0.055195 & $\mathrm{CR}$ & 0.04451 & & \\
\hline
\end{tabular}

TABLE 9: Indicator judgement matrix and the weights of the ecological risk.

\begin{tabular}{lccccccc}
\hline$U_{5}$ & $U_{51}$ & $U_{52}$ & $U_{53}$ & $U_{54}$ & $U_{55}$ & $U_{56}$ & $\omega$ \\
\hline$U_{51}$ & 0.715 & 0.1966 & 0.1966 & 0.0563 & 0.0563 & 0.1047 & 0.0230 \\
$U_{52}$ & 2.7137 & 0.715 & 0.3729 & 0.1966 & 0.1966 & 0.3729 & 0.0743 \\
$U_{53}$ & 2.7137 & 1.3856 & 0.715 & 0.1966 & 0.1966 & 0.3729 & 0.0924 \\
$U_{54}$ & 10.7297 & 2.7137 & 2.7137 & 0.715 & 1.3856 & 2.7137 & 0.3771 \\
$U_{55}$ & 10.7297 & 2.7137 & 2.7137 & 0.3729 & 0.715 & 1.3856 & 0.2788 \\
$U_{56}$ & 5.3698 & 1.3856 & 1.3856 & 0.1966 & 0.3729 & 0.715 & 0.1434 \\
$\lambda$ & 6.25713 & $\mathrm{CI}$ & 0.05142 & $\mathrm{CR}$ & 0.04147 & & \\
\hline
\end{tabular}

The classic risk assessment method for PPP projects is concerned with sequencing and scope of project risks [33], and the advantages of the cloud model are highlighted. The Pythagorean fuzzy cloud model not only determines the level of project risk but also can generate risk in the form of a 
TABLE 10: Cloud eigenvalues of the indicator system.

\begin{tabular}{|c|c|c|c|}
\hline $\begin{array}{l}1^{\text {st }} \text {-level risk } \\
\text { indicator }\end{array}$ & Eigenvalue & $\begin{array}{c}2^{\text {nd }} \text {-level risk } \\
\text { indicator }\end{array}$ & Eigenvalue \\
\hline$U_{1}$ Political risk & $\begin{array}{c}(72.56,4.27 \\
0.5)\end{array}$ & $\begin{array}{c}U_{11} \text { Legislative } \\
\text { changes } \\
U_{12} \text { Government } \\
\text { intervention } \\
U_{13} \text { Land } \\
\text { acquisition } \\
U_{14} \text { Unstable law } \\
\text { or rules }\end{array}$ & $\begin{array}{c}(80.20,4.81, \\
0.5) \\
(65.40,2.41, \\
0.5) \\
(82.00,4.01, \\
0.5) \\
(26.20,2.81, \\
0.5) \\
\end{array}$ \\
\hline $\begin{array}{l}U_{2} \text { Economic } \\
\text { risk }\end{array}$ & $\begin{array}{c}(40.55,1.36 \\
0.5)\end{array}$ & $\begin{array}{c}U_{21} \text { Interest rate } \\
U_{22} \text { Financial/ } \\
\text { exchange rate risk } \\
U_{23} \text { Inflation risk } \\
U_{24} \text { Land } \\
\text { compensation } \\
\text { standard }\end{array}$ & $\begin{array}{c}(34.40,1.10, \\
0.5) \\
(80.00,4.01, \\
0.5) \\
(33.40,3.11, \\
0.5) \\
(31.40,1.10, \\
0.5)\end{array}$ \\
\hline $\begin{array}{l}U_{3} \text { Construction } \\
\text { completion risk }\end{array}$ & $\begin{array}{c}(64.75,2.80 \\
0.5)\end{array}$ & $\begin{array}{c}U_{31} \text { Technology } \\
\text { risk } \\
U_{32} \text { Construction } \\
\text { cost overrun } \\
U_{33} \text { Delay in } \\
\text { supply } \\
U_{34} \text { Project quality } \\
\text { risk }\end{array}$ & $\begin{array}{c}(65.40, \\
1.40,0.5) \\
(79.80,5.21, \\
0.5) \\
(27.20, \\
1.70,0.5) \\
(65.00,3.01, \\
0.5) \\
\end{array}$ \\
\hline $\begin{array}{l}U_{4} \text { Operational } \\
\text { risk }\end{array}$ & $\begin{array}{c}(61.23,1.70 \\
0.5)\end{array}$ & $\begin{array}{c}U_{41} \text { Profit risk } \\
U_{42} \text { Operation } \\
\text { management risk } \\
U_{43} \text { Default risk } \\
U_{44} \text { Supporting } \\
\text { facilities } \\
U_{45} \text { Operator } \\
\text { change } \\
U_{46} \text { Operation cost } \\
\text { overrun }\end{array}$ & $\begin{array}{c}(65.00, \\
1.50,0.5) \\
(64.40,3.11, \\
0.5) \\
(26.60,1.41, \\
0.5) \\
(65.40,2.41, \\
0.5) \\
(66.00, \\
1.50,0.5) \\
(67.20, \\
1.70,0.5) \\
\end{array}$ \\
\hline $\begin{array}{l}U_{5} \text { Ecological } \\
\text { risk }\end{array}$ & $\begin{array}{c}(53.08,2.71 \\
0.5)\end{array}$ & $\begin{array}{c}U_{51} \text { Landscaping } \\
\text { risk } \\
U_{52} \text { Soil erosion } \\
U_{53} \text { Biological } \\
\text { chain destruction } \\
U_{54} \text { Water } \\
\text { pollution } \\
U_{55} \text { Solid waste } \\
\text { pollution } \\
U_{56} \text { Public } \\
\text { perception and } \\
\text { involvement }\end{array}$ & $\begin{array}{c}(32.80, \\
1.80,0.5) \\
(33.40,1.91, \\
0.5) \\
(31.20,1.30, \\
0.5) \\
(64.60,3.11, \\
0.5) \\
(65.20,2.31, \\
0.5) \\
(26.80,2.31, \\
0.5)\end{array}$ \\
\hline Project risk & $\begin{array}{c}(65.52, \\
4.12,0.5)\end{array}$ & & \\
\hline
\end{tabular}

cloud. This model blurs the boundary of the risk and makes the assessment no longer a simple list. The following analysis will discuss the results that combine the eigenvalues of the second-level index in Table 10 and their figures (Figures 4-8). The analysis below is ordered from the highest

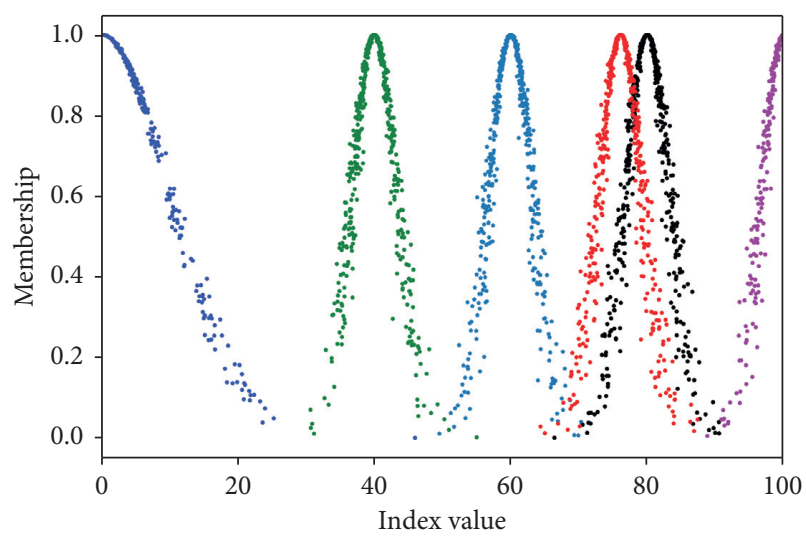

FIGURE 5: Cloud map of political risk.

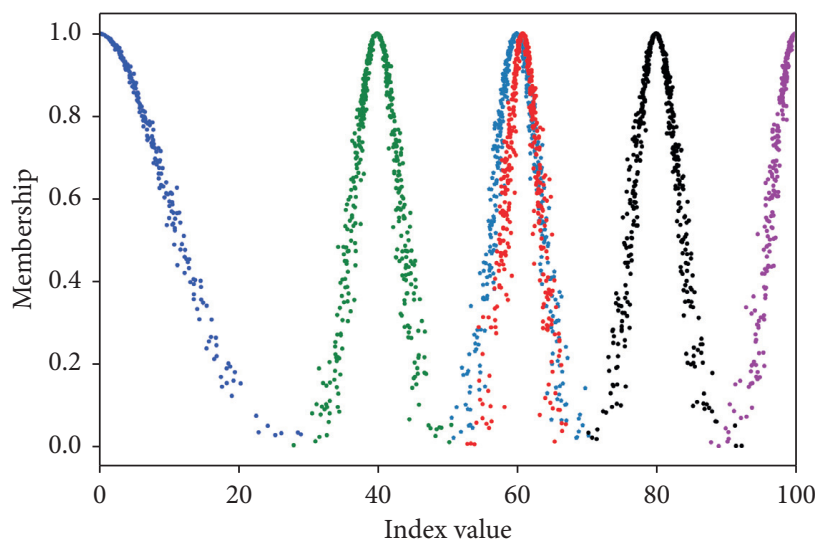

Figure 6: Cloud map of economic risk.

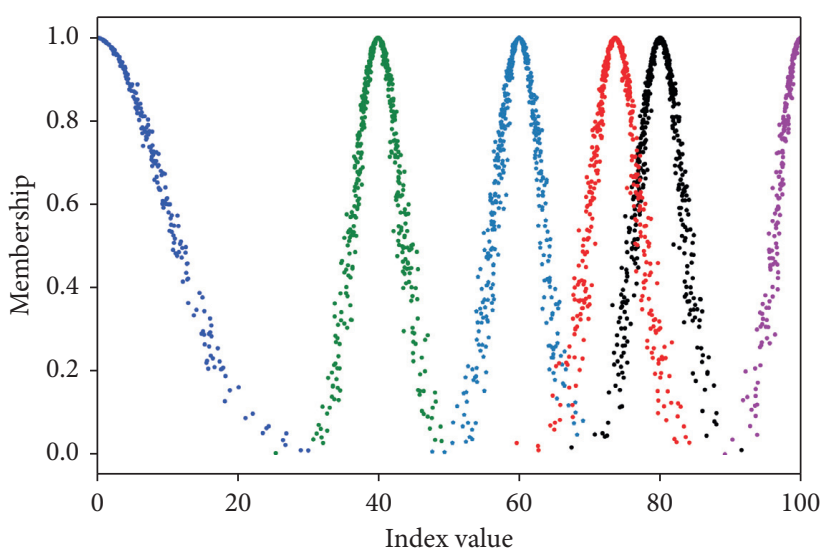

FIGURE 7: Cloud map of construction completion risk.

risk level to the lowest according to the eigenvalues of the indicators. The higher the value of $E_{x}$, the more critical the factor.

For the political risk aspect, its risk cloud falls between the medium and medium-high risk thresholds, as shown in Figure 5. The cloud crosses the medium risk cloud below the membership of 0.2 ; then, it crosses the medium-high risk cloud with a membership over 0.8. Comparing the 


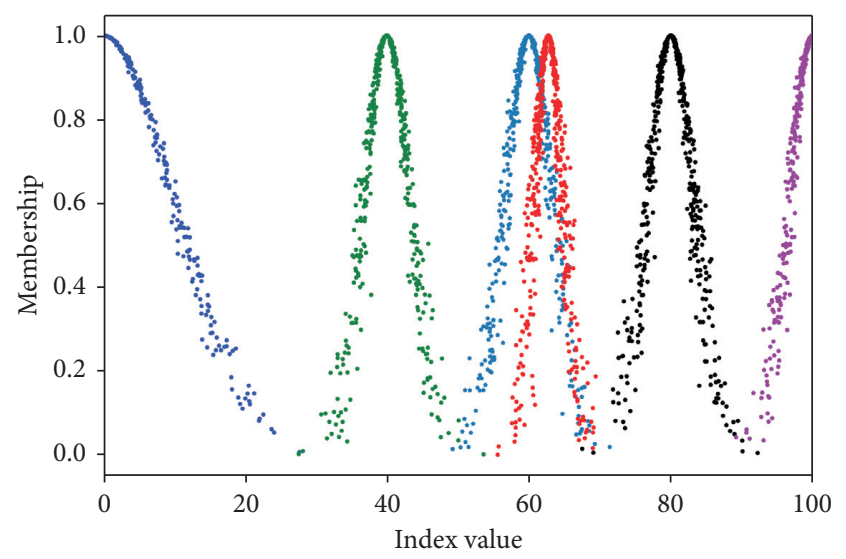

FIGURE 8: Cloud map of operational risk.

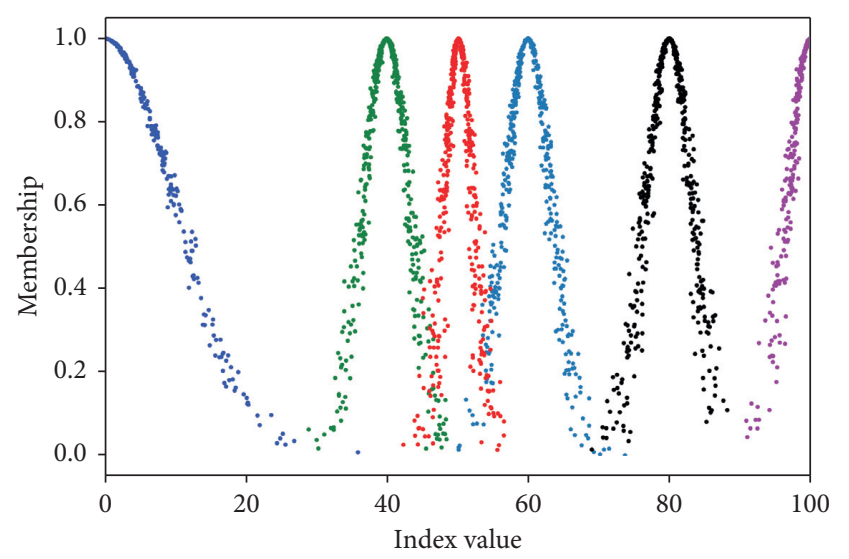

Figure 9: Cloud map of ecological risk.

eigenvalues of the secondary index in Table 10, legislative change $(80.20,4.81,0.5)$, land compensation $(82.00,4.01$, $0.5)$, and government intervention $(65.40,2.41,0.5)$ were found to be critical. As public welfare projects, water environment treatment projects have a simple rate of return, and they are usually funded by the Chinese government. Therefore, government compensation and policy changes have a great impact on PPP projects. Like China's Olympic Stadium, the "Bird's Nest" [72] and "Citong Bridge" [73] are typical PPP projects that have been unsuccessful due to policy implications and inadequate incentives. For the government, it is recommended to participate in a subordinate role and to introduce a third-party regulatory agent to assist with the project. For research institutes, scholars may focus more on the optimization of the compensation mechanism. For the private sector, to avoid risk from the government, a long-term legislative contract is indispensable. More importantly, a sound legal mechanism can make the contract more resistant to risks.

With regard to the construction completion risk aspect, see Figure 7, its cloud intersects with the medium risk below the membership of 0.2 , and it crosses the medium-high risk standard cloud between the memberships of 0.6 and 0.8 , which means that the construction completion risk is almost in the medium-high risk rank. Comparing the eigenvalues of

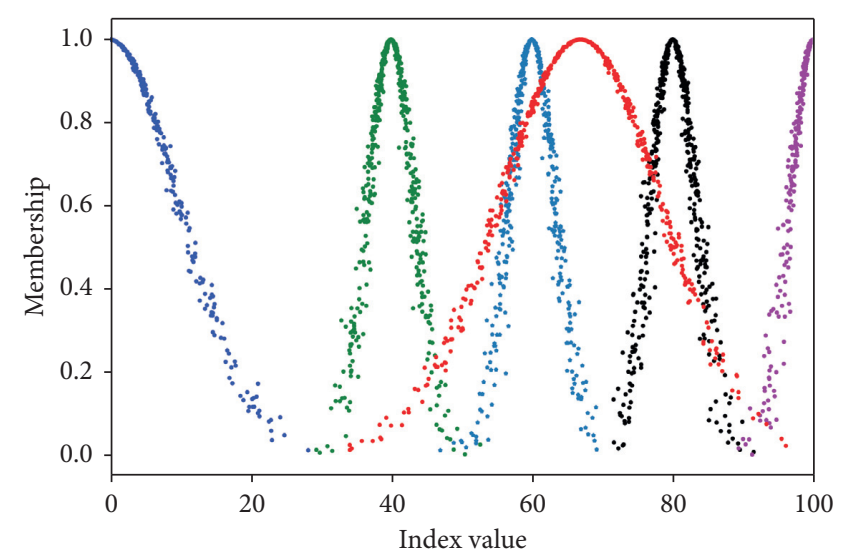

Figure 10: Cloud map of total project risk.

the secondary index in Table 10, construction cost overrun (79.80, 5.21, 0.5) was found to pose the most critical risk. Therefore, contractors should declare the budget and sign a "turn-key contract" with the private consortium. In that case, the private consortium would no longer be responsible for any additional payments during the construction period. In addition, a clear settlement date should be specified in the contract with a detailed list of costs and reasonable incentives. In order to avoid loss from technology risk $(65.40,1.40$, $0.5)$, choosing an experienced and reliable contractor is necessary. Furthermore, the contractor needs to ensure the effectiveness of current technology for the duration of the project and not experiment with nascent technologies. To ensure construction quality, private consortiums should choose a reliable contractor with a good reputation.

Operational risk is assessed as a medium risk level, see Figure 8. Its cloud crosses the medium cloud with a membership between 0.6 and 0.8 , and it intersects with the medium-high cloud below 0.2 , in which the eigenvalue is $(61.23,1.70,0.5)$. Comparing the eigenvalues of the secondary index in Table 10, five $E_{x}$ values for the second-level indicators are over 60 . They are the following: cost overrun $(67.20,1.70,0.5)$, operator change $(66.00,1.50,0.5)$, supporting facilities $(65.40,2.41,0.5)$, profit risk $(65.00,1.50$, $0.5)$, and operation management risk $(64.40,3.11,0.5)$. First, in the context of China's rapid economic development, the risk of exceeding the budget will occur during a long operating period. The private sector may win the bid for a PPP project by reducing their cost. Postponed construction is another cause of an overrun budget. Second, after the project is designed, the contract between the government and the private sector will identify the operating sector. The operating company may offer to withdraw from the project due to its own financial problems or because of conflicts with the builder in the previous phase. Third, inadequate and unmatched facilities often are an issue in Chinese infrastructure projects. This requires the project management company to focus on the links between each department. Fourth, profit sharing is a big topic in PPP research, and a fair benefit distribution agreement can effectively alleviate the cooperation contradiction between the public and private sectors. If this is not done, it will cause risks. Finally, the 
TABLE 11: Comparison of the AHP cloud model and the PFAHP cloud model: assessment.

\begin{tabular}{lcc}
\hline & $\begin{array}{c}\text { Cloud model with } \\
\text { AHP }\end{array}$ & $\begin{array}{c}\text { Cloud model with } \\
\text { PFAHP }\end{array}$ \\
\hline $\begin{array}{l}\text { Total risk } \\
\text { level }\end{array}$ & MEDIUM & MEDIUM \\
\hline
\end{tabular}

PPP mode in China is, in fact, still in the exploration stage. Nonetheless, PPP projects need highly talented personnel with operation and management skills. Thus, universities could expand related faculty to cultivate synthesized talent. The operation period is the longest one in a PPP project's life cycle, and all stakeholders need to strengthen their legal awareness of the key risks identified when formulating the contract.

From the ecological perspective, see Figure 9, the cloud is primarily located in the low risk rank, with a membership of below 0.2 , though a small amount of it is in the medium risk rank, with a membership between 0.2 and 0.4. Comparing the eigenvalues of the secondary index in Table 10, we found that water pollution $(64.60,3.11,0.5)$ and solid waste risks $(65.20,2.31,0.5)$ are the most significant. In our case study, Xuchang, China, was denoted as a fourth-tier city, with pollution coming mostly from citizens. For example, the nearby factories dump unqualified products directly into the river, which has led to serious pollution for a long time. Additionally, it was reported that residents often do laundry and wash their cars in the river, which has led to chemical pollution of the river. The local government and media should work together to spread knowledge to local residents and visitors about sustainable human behaviors and how they affect our living environment. At the same time, NGOs could take on the responsibility of monitoring the pollution. From the technology perspective, the government is recommended to provide more funding to academic institutions for innovative sewage and solid waste treatment technologies.

For the economic risk dimension, the cloud is basically within the medium risk rank and has a small distribution, as shown in Figure 6, with an eigenvalue of $(40.55,1.36,0.5)$. Comparing the eigenvalues of the second-level indicators in Table 10, we found that financing risk $(80.00,4.01,0.5)$ is the most critical factor. Equity financing and debt financing are two options in project financing. Equity financing is derived from a company's capital, and its purpose is to enhance the ability of the operating company to mitigate risk and expand project scale. On the contrary, debt financing is mainly aimed at expanding project scale and obtaining cash flow during a project's operating period. Water environment treatment projects were mostly funded by the Chinese government in the earliest days of the nation. It was not until the early 1980s that PPP projects were developed in China, and such projects have accumulated experience in equity investment. However, China's bond market is still immature. A PPP project is likely to be refinanced or debt financed, during its long operating period. With regard to debt financing, syndicated loans are flexible and efficient. They can customize relevant terms to various private investors. Ke [38] mentioned the usage of syndicated loans in PPP financing early on, but they are still not the main force in the Chinese credit market. In the meanwhile, the government has suggested providing incentives, tax reductions, and exemptions to lower the entry barriers for private enterprises.

\section{Conclusion}

Water environment treatment PPP projects have been acknowledged as a crucial aspect of China's infrastructure projects. With the rapid development of the economy and society, the problem of water environment pollution in China has increased in severity. Water environment treatment PPP projects have fully received the attention of the Chinese government. The application of the PPP model has brought significant funds to such projects. Therefore, a scientific assessment method of the risks of water environment treatment PPP projects can reduce the losses to all stakeholders.

Due to problems caused by the fuzziness and randomness of the index and evaluation language set in traditional risk assessment, the cloud model was adopted to deal with the above problems for the index system. This paper first constructed a risk evaluation indicator system for water environment treatment PPP projects. After collecting risk ratings from experts and decision makers about the risks of PPP projects in water environment governance, the weights of these risks were calculated using a Pythagorean fuzzy AHP. Later, the cloud model eigenvalues of the firstand second-level indexes were calculated using the floating cloud algorithm and the comprehensive cloud algorithm. Moreover, some visual cloud maps were obtained according to the backward cloud generator. Finally, some suggestions were developed to evaluate the risks of the Yinma River water environment treatment PPP project. The results show that the project is considered to be a "Medium" risk, with an eigenvalue of $(65.52,4.12,0.5)$, and Political risk $>$ Construction completion risk $>$ Operational risk $>$ Ecological risk $>$ Economic risk. Based on these results, the factors under each first-level indicator were discussed.

This paper makes two important contributions. First, it identifies unique risk factors of water environment treatment PPP projects, which make up for the lack of industry background in current risk assessment research. Secondly, a new risk assessment cloud model was constructed by using PFS, in which it was found that ecological risk was more critical than economic risk, providing a new approach for risk assessment in PPP projects. First-level risk indicators, when using regular AHP in a cloud model, are ordered as $U_{1}>U_{3}>U_{4}>U_{2}>U_{5}$, while the order is $U_{1}>U_{3}>U_{4}>U_{5}>U_{2}$ when using PFAHP. Such results reflect the advantages of using the PFS in the cloud model in water environment treatment projects, for its ecological risk $\left(U_{5}\right)$ might have been ignored in the classic methods. Thus, the results of this study are conducive to creating a more accurate and scientific risk assessment method. The detailed eigenvalues are listed in Supplementary material. Finally, 
this paper provides a new angle for the theory and empirical study of risk assessment in water environment treatment PPP projects, which has both theoretical and practical value. Meanwhile, this paper also has some limitations. In the process of gathering expert ratings, the membership function of the language variables depended on the perception of experts, which entails a certain degree of subjectivity. In future studies, multigranularity linguistics could be considered to expand the evaluation linguistic set.

\section{Data Availability}

The data used to support the findings of this study are available from the corresponding author upon request.

\section{Conflicts of Interest}

The authors declare that there are no conflicts of interest regarding the publication of this paper.

\section{Acknowledgments}

The authors acknowledge with gratitude for the support from the Philosophy and Social Science Research Project of Universities in Henan Province (2017-YYZD-04), China Scholarship Council (no. 20190001316), Social Science Project of Henan Province (2020JJX26), and the PhD Innovation Fund of North China University of Water Resources and Electric Power (2019). The authors thank Mr. Wu Yangkai for his inspiration and all the co-authors' help.

\section{Supplementary Materials}

Appendix 1. Questionnaire of risk identification Part I: Background of interviewees. Appendix 2. Comparison of AHP cloud model and PFAHP cloud model: eigenvalues. (Supplementary Materials)

\section{References}

[1] H. H. Savenije, "Why water is not an ordinary economic good, or why the girl is special," Physics and Chemistry of the Earth, Parts A/B/C, vol. 27, no. 11-22, pp. 741-744, 2002.

[2] R. Shams Eldin, H. Osman, and M. Georgy, "Identification and ranking of risk factors encountered by water sector PPP projects in Egypt," Journal of Engineering and Applied Science, vol. 66 , no. 2, pp. 243-264, 2019.

[3] M. Marzouk and M. Ali, "Mitigating risks in wastewater treatment plant PPPs using minimum revenue guarantee and real options," Utilities Policy, vol. 53, pp. 121-133, 2018.

[4] J.-h. Choi, J. Chung, and D.-J. Lee, "Risk perception analysis: participation in China's water PPP market," International Journal of Project Management, vol. 28, no. 6, pp. 580-592, 2010.

[5] A. Shrestha, T. K. Chan, A. A. Aibinu, C. Chen, and I. Martek, "Risk allocation inefficiencies in Chinese PPP water projects," Journal of Construction Engineering Management Accounting Research, vol. 144, no. 4, 2018.

[6] B.-G. Hwang, X. Zhao, and M. J. S. Gay, "Public private partnership projects in Singapore: factors, critical risks and preferred risk allocation from the perspective of contractors,"
International Journal of Project Management, vol. 31, no. 3, pp. 424-433, 2013.

[7] N. Qian, S. House, A. M. Wu, and X. Wu, "Public-private partnerships in the water sector in China: a comparative analysis," International Journal of Water Resources Development, vol. 36, no. 4, pp. 631-650, 2020.

[8] J. Yin, X. Bai, and M. Yuan, "Construction and application of risk assessment system for environmental PPP projects," IOP Conference Series: Earth and Environmental Science, vol. 242, Article ID 052005, 2019.

[9] X. An, H. Li, L. Wang, Z. Wang, J. Ding, and Y. Cao, "Compensation mechanism for urban water environment treatment PPP project in China," Journal of Cleaner Production, vol. 201, no. 1-1166, pp. 246-253, 2018.

[10] Y. Xu, Y. Yang, A. P. C. Chan, J. F. Y. Yeung, and H. Cheng, "Identification and allocation of risks associated with ppp water projects in China/su kinijos vandens projektais, pagrịstais viešojo Ir privačiojo sektoriụ partneryste, susijusiụ rizikos rūšiụ nustatymas Ir paskirstymas," International Journal of Strategic Property Management, vol. 15, no. 3, pp. 275-294, 2011.

[11] A. Nguyen, A. Mollik, and Y.-Y. Chih, "Managing critical risks affecting the financial viability of public-private partnership projects: case study of toll road projects in vietnam," Journal of Construction Engineering and Management, vol. 144, no. 12, Article ID 05018014, 2018.

[12] O. S. AI-Sobiei, Assessment of Risk Allocation in Construction Projects, 2002.

[13] E. E. Ameyaw and A. P. C. Chan, "A fuzzy approach for the allocation of risks in public-private partnership water-infrastructure projects in developing countries," Journal of Infrastructure Systems, vol. 22, no. 3, Article ID 04016016, 2016.

[14] E. E. Ameyaw and A. P. C. Chan, "Evaluation and ranking of risk factors in public-private partnership water supply projects in developing countries using fuzzy synthetic evaluation approach," Expert Systems with Applications, vol. 42, no. 12, pp. 5102-5116, 2015.

[15] E. E. Ameyaw and A. P. C. Chan, "Evaluating key risk factors for PPP water projects in Ghana: a Delphi study," Journal of Facilities Management, vol. 13, no. 2, pp. 133-155, 2015.

[16] J. Li and P. X. W. Zou, "Fuzzy AHP-based risk assessment methodology for PPP projects," Journal of Construction Engineering and Management, vol. 137, no. 12, pp. 1205-1209, 2011.

[17] J. Yuan, Y. Zeng, X. Guo, Y. Ai, and M. Xiong, "Electric power investment risk assessment for belt and road initiative nations," Sustainability, vol. 10, no. 9, p. 3119, 2018.

[18] Z. Han, J. D. Porras-Alvarado, J. Sun, and Z. Zhang, "Monte Carlo simulation-based assessment of risks associated with public-private partnership investments in toll highway infrastructure," Transportation Research Record: Journal of the Transportation Research Board, vol. 2670, no. 1, pp. 59-67, 2017.

[19] S. T. Ng, J. Xie, Y. K. Cheung, and M. Jefferies, “A simulation model for optimizing the concession period of public-private partnerships schemes," International Journal of Project Management, vol. 25, no. 8, pp. 791-798, 2007.

[20] W. Zou, M. Kumaraswamy, J. Chung, and J. Wong, "Identifying the critical success factors for relationship management in PPP projects," International Journal of Project Management, vol. 32, no. 2, pp. 265-274, 2014.

[21] C. Cui, Y. Liu, A. Hope, and J. Wang, "Review of studies on the public-private partnerships (PPP) for infrastructure 
projects," International Journal of Project Management, vol. 36, no. 5, pp. 773-794, 2018.

[22] Y. Xu, J. F. Y. Yeung, A. P. C. Chan, D. W. M. Chan, S. Q. Wang, and Y. Ke, "Developing a risk assessment model for PPP projects in China - a fuzzy synthetic evaluation approach," Automation in Construction, vol. 19, no. 7, pp. 929-943, 2010.

[23] A. P. C. Chan, J. F. Y. Yeung, C. C. P. Yu, S. Q. Wang, and Y. Ke, "Empirical study of risk assessment and allocation of public-private partnership projects in China," Journal of Management in Engineering, vol. 27, no. 3, pp. 136-148, 2011.

[24] A. V. Thomas, S. N. Kalidindi, and L. S. Ganesh, "Modelling and assessment of critical risks in BOT road projects," Construction Management \& Economics, vol. 24, no. 4, pp. 407424, 2006.

[25] Y. Wu, C. Xu, L. Li, Y. Wang, K. Chen, and R. Xu, “A risk assessment framework of PPP waste-to-energy incineration projects in China under 2-dimension linguistic environment," Journal of Cleaner Production, vol. 183, pp. 602-617, 2018.

[26] A. Valipour, N. Yahaya, N. Md Noor, J. Antuchevičiené, and J. Tamošaitienè, "Hybrid SWARA-COPRAS method for risk assessment in deep foundation excavation project: an Iranian case study," Journal of Civil Engineering and Management, vol. 23, no. 4, pp. 524-532, 2017.

[27] Y. Wu, Z. Song, L. Li, and R. Xu, "Risk management of publicprivate partnership charging infrastructure projects in China based on a three-dimension framework," Energy, vol. 165, pp. 1089-1101, 2018.

[28] Y. Li and X. Wang, "Using fuzzy analytic network process and ISM methods for risk assessment of public-private partnership: a China perspective," Journal of Civil Engineering and Management, vol. 25, no. 2, pp. 168-183, 2019.

[29] L. Deyi, M. Haijun, and S. Xuemei, "Membership clouds and membership cloud generators," Journal of Computer Research and Development, vol. 6, no. 32, pp. 15-20, 1995.

[30] A.-H. Khameneh, A. Taheri, and M. Ershadi, "Offering a framework for evaluating the performance of project risk management system," Procedia - Social and Behavioral Sciences, vol. 226, no. 226, pp. 82-90, 2016.

[31] D. E. Garrick, J. W. Hall, A. Dobson et al., "Valuing water for sustainable development," Science, vol. 358, no. 6366, pp. 1003-1005, 2017.

[32] C. Sassine, "A framework to evaluate the financial viability of urban public-private partnership projects," in Faculty of the Graduate SchoolUniversity of Texas, Austin, TX, USA, 2015.

[33] H. Li, Q. Xia, S. Wen, L. Wang, and L. Lv, "Identifying factors affecting the sustainability of water environment treatment public-private partnership projects," Advances in Civil Engineering, vol. 2019, Article ID 7907234, 15 pages, 2019.

[34] E. E. Ameyaw and A. P. C. Chan, "Evaluation and ranking of risk factors in public-private partnership water supply projects in developing countries using fuzzy synthetic evaluation approach," Expert Systems with Applications, vol. 42, no. 12, pp. 5102-5116, 2015.

[35] F. Medda, "A game theory approach for the allocation of risks in transport public private partnerships," International Journal of Project Management, vol. 25, no. 3, pp. 213-218, 2007.

[36] A. $\mathrm{Ng}$ and M. Loosemore, "Risk allocation in the private provision of public infrastructure," International Journal of Project Management, vol. 25, no. 1, pp. 66-76, 2007.

[37] Y. Xu, A. P. C. Chan, and J. F. Y. Yeung, "Developing a fuzzy risk allocation model for PPP projects in China," Journal of
Construction Engineering and Management, vol. 136, no. 8, pp. 894-903, 2010.

[38] Y. Ke, S. Wang, A. P. C. Chan, and E. Cheung, "Understanding the risks in China's PPP projects: ranking of their probability and consequence," Engineering, Construction and Architectural Management, vol. 18, no. 5, pp. 481-496, 2011.

[39] J. Song, D. Song, X. Zhang, and Y. Sun, "Risk identification for PPP waste-to-energy incineration projects in China," Energy Policy, vol. 61, pp. 953-962, 2013.

[40] B. Li, A. Akintoye, P. J. Edwards, and C. Hardcastle, "The allocation of risk in PPP/PFI construction projects in the UK," International Journal of Project Management, vol. 23, no. 1, pp. 25-35, 2005.

[41] J. Song, D. Song, X. Zhang, and Y. Sun, "Risk identification for PPP waste-to-energy incineration projects in China," Energy Policy, vol. 61, pp. 953-962, 2013.

[42] A. P. C. Chan, E. H. K. Yung, P. T. I. Lam, C. M. Tam, and S. O. Cheung, "Application of Delphi method in selection of procurement systems for construction projects," Construction Management \& Economics, vol. 19, no. 7, pp. 699-718, 2001.

[43] G. Heravi, M. Fathi, and S. Faeghi, "Evaluation of sustainability indicators of industrial buildings focused on petrochemical projects," Journal of Cleaner Production, vol. 109, no. 16, pp. 92-107, 2015.

[44] B.-G. Hwang, X. Zhao, and M. J. S. Gay, "Public private partnership projects in Singapore: factors, critical risks and preferred risk allocation from the perspective of contractors," International Journal of Project Management, vol. 31, no. 3, pp. 424-433, 2013.

[45] R. J. Yang and P. X. W. Zou, "Stakeholder-associated risks and their interactions in complex green building projects: a social network model," Building and Environment, vol. 73, pp. 208-222, 2014.

[46] A. A. Aziz and T. L. Shen, "Management of force majeure risks in Canadian PPP transportation projects," Construction Research Congress, 2016.

[47] X. Yelin, A. P. C. Chan, X. Bo, K. Queena, Y. Liu, and Y. Peng, "Critical risk factors affecting the implementation of PPP waste-to-energy projects in China," Applied Energy, vol. 158, pp. 403-411, 2015.

[48] M. Yilmaz and A. Bakis, "Sustainability in construction sector," Procedia Social and Behavioral Sciences, vol. 195, pp. 2253-2262, 2015.

[49] G. Fernández-Sánchez and F. Rodríguez-López, "A methodology to identify sustainability indicators in construction project management-Application to infrastructure projects in Spain," Ecological Indicators, vol. 10, no. 6, pp. 1193-1201, 2010.

[50] J. P. Walters and A. N. Javernick-Will, "Long-term functionality of rural water services in developing countries: a system dynamics approach to understanding the dynamic interaction of factors," Environmental Science and Technology, vol. 49, no. 8, pp. 5035-5043, 2015.

[51] J. Kivila, M. Martinsuo, and L. Vuorinen, "Sustainable project management through project control in infrastructure projects," International Journal of Project Management, vol. 35, no. 6, pp. 1167-1183, 2017.

[52] S. Yu and H. Lu, "Integrated watershed management through multi-level and stepwise optimization for allocation of total load of water pollutants at large scales," Environmental Earth Sciences, vol. 77, no. 10, p. 373, 2018.

[53] R. Kiani Mavi and C. Standing, "Critical success factors of sustainable project management in construction: a fuzzy 
DEMATEL-ANP approach," Journal of Cleaner Production, vol. 194, no. 1, pp. 751-765, 2018.

[54] L. Shen, Y. Wu, and X. Zhang, "Key assessment indicators for the sustainability of infrastructure projects," Journal of Construction Engineering and Management, vol. 137, no. 6, pp. 441-451, 2011.

[55] L. Wang, F. Zhang, S. Fu et al., "Assessment of soil erosion risk and its response to climate change in the mid-Yarlung Tsangpo River region," Environmental Science and Pollution Research, vol. 27, no. 1, pp. 607-621, 2020.

[56] C. P. Tung, T. C. Lee, and W. T. Liao, "Climate change impact assessment for sustainable water quality management," Terrestrial, Atmospheric and Oceanic Sciences, vol. 23, no. 5, pp. 565-576, 2012.

[57] ANDI, "The importance and allocation of risks in Indonesian construction projects," Construction Management and Economics, vol. 24, no. 1/3, pp. 69-80, 2006.

[58] N. A. Kartam and S. A. Kartam, "Risk and its management in the Kuwaiti construction industry: a contractors' perspective," International Journal of Project Management, vol. 19, no. 6, pp. 325-335, 2001.

[59] S. Zhang, M. Xiang, Z. Xu, L. Wang, and C. Zhang, "Evaluation of water cycle health status based on a cloud model," Journal of Cleaner Production, vol. 245, Article ID 118850, 2020.

[60] B. Yang and Z. Y. Zhu, "Mining multilevel spatial association rules with cloud models," Journal of Harbin Institute of Technology, vol. 12, no. 3, pp. 314-318, 2005.

[61] S. Zhang, M. Xiang, Z. Xu, L. Wang, and C. Zhang, "Evaluation of water cycle health status based on a cloud model," Journal of Cleaner Production, vol. 245, no. 1, Article ID 118850, 2020.

[62] K. Cheng, F. U. Qiang, and Y. Ren, "Evaluation of bearing capacity of water resources in Heilongjiang province based on entropy weight and cloud model," Journal of Northeast Agricultural University, vol. 46, no. 8, pp. 75-80, 2015.

[63] D.-y. Li, C.-Y. Liu, and L. Liu, "Study on the universality of the normal cloud model," Engineering and Science, vol. 6, no. 8, pp. 28-34, 2004.

[64] H. Sung-Lin and Y. Min-Ren, "A multimethodology contractor assessment model for facilitating green innovation: the view of energy and environmental protection," The Scientific World Journal, vol. 2013, Article ID 624340, 2013.

[65] R. R. Yager, "Pythagorean membership grades in multicriteria decision making," IEEE Transactions on Fuzzy Systems, vol. 22, no. 4, pp. 958-965, 2014.

[66] R. R. Yager, "Prioritized aggregation operators," International Journal of Approximate Reasoning, vol. 48, no. 1, pp. 263-274, 2008.

[67] R. R. Yager and A. M. Abbasov, "Pythagorean membership grades, complex numbers, and decision making," International Journal of Intelligent Systems, vol. 28, no. 5, pp. 436452, 2013.

[68] X. Zhang and Z. Xu, "Extension of TOPSIS to multiple criteria decision making with Pythagorean fuzzy sets," International Journal of Intelligent Systems, vol. 29, no. 12, pp. 1061-1078, 2014.

[69] A. Karasan, E. Ilbahar, S. Cebi, and C. Kahraman, "A new risk assessment approach: safety and Critical Effect Analysis (SCEA) and its extension with Pythagorean fuzzy sets," Safety Science, vol. 108, pp. 173-187, 2018.

[70] S. Luo, G. Liu, and B. Zhang, "Evaluation model of digital map quality based on cloud model," Journal of Geomatics Science and Technology, vol. 25, no. 2, pp. 123-126, 2008.
[71] R. K. Yin, Case Study Research: Design and Methods, John Wiley \& Sons, Ltd., Hoboken, NJ, USA, 2009.

[72] W. Liang, X. Y. Song, and S. Q. Wang, "Case study of the bird's nest: risks and opportunities in China's PPP implementations in major sports facilities," Advanced Materials Research, vol. 243-249, pp. 6332-6338, 2011.

[73] B. Li, "Challenges of private domestic finance in developing infrastructure projects in China," in Proceedings of the 2007 International Conference on Concession Public/Infrastructure Projects, pp. 121-130, Dalian, China, August 2007. 